\title{
Laser polishing of additive manufactured Ti6Al4V alloy: a review
}

\author{
Jiejing Li॰ and Dunwen Zuo* \\ Nanjing University of Aeronautics and Astronautics, College of Mechanical and \\ Electrical Engineering, Nanjing, China
}

\begin{abstract}
Additive manufactured Ti6Al4V alloy has excellent comprehensive properties and has broad application prospects in the aerospace, biomedicine, and other fields. However, the fabricated components are too rough to use directly. So, a corresponding postprocess is needed urgently. The conventional finishing process cannot meet the requirements of green and efficient processing because of its time consumption, environmental pollution, and low productivity. Laser polishing, as a highly efficient and noncontact post-treatment technology, has attracted more and more attention in the polishing of additive manufactured Ti6Al4V alloy. The research of laser polishing of Ti6Al4V alloy in recent years has expatiated and includes laser polishing mechanisms, surface roughness and morphology, microstructure, mechanical properties, and finite element simulation analysis during laser polishing. Furthermore, the existing challenges of laser-polished Ti6Al4V alloy are summarized, and future development directions are proposed. (C) 2021 Society of Photo-Optical Instrumentation Engineers (SPIE) [DOI: 10.1117/1.OE.60.2 .020901]
\end{abstract}

Keywords: additive manufacturing; laser polishing; surface topography; mechanical properties; simulation analysis.

Paper 20201104V received Sep. 17, 2020; accepted for publication Dec. 23, 2020; published online Feb. 8, 2021.

\section{Introduction}

Additive manufacturing (AM) is a revolutionary technology that has developed rapidly in recent decades. ${ }^{1}$ Because of its important applications in aerospace, automobile manufacturing, biomedical science, and so on, it has been one of the most promising and powerful technologies. ${ }^{2-4}$ The AM technologies used for Ti6Al4V include selective electron beam melting, ${ }^{5}$ direct metal deposition, ${ }^{6}$ and selective laser melting (SLM). ${ }^{7}$ SLM is one of the most commonly used methods in AM; it is a rapid melting and cooling solidification technology of metal powders under the action of a high energy laser beam. In the SLM process, the laser performs a single-point scan along the given route and generates complex three-dimensional (3D) parts by selectively melting successive layers of metal powder. The way of near-net-forming reduces the subsequent machining and the production cost. ${ }^{8-10}$ Especially in aerospace and medical applications, SLM provides flexibility for the design and processing of aircraft parts and implants due to its complex geometry, huge individual differences, and high prices. ${ }^{11}$ Furthermore, SLM can manufacture parts without any special tools, shorten the design and production cycle, and realize free and efficient machining. ${ }^{12}$ SLM technology can also produce multimaterial components, which is called multimaterial printing, to meet specific applications. ${ }^{13}$ Multimaterial design can be used in fusion reactors ${ }^{14}$ and the automobile and aviation industries, ${ }^{15}$ but multimetal components with AM still face many challenges. Enormous efforts in multimaterial AM are still needed to solve the processing defects. ${ }^{16,17}$

Many kinds of metallic materials are used to fabricate parts with complex geometry and high dimensional accuracy in AM. Titanium alloys are very popular among them, especially Ti6Al4V because it has a lot of excellent characteristics, such as corrosion resistance, small density, high specific strength, good toughness, and high biocompatibility. ${ }^{18-21} \mathrm{Ti6Al4V}$ is applicable in areas

*Address all correspondence to Dunwen Zuo, imit505@nuaa.edu.cn 
of aerospace, shipbuilding, biomedical, and so on. For example, in the field of aerospace, titanium alloy is used to manufacture the aircraft frame, hatch door, rocket engine shell, etc. Nevertheless, due to the complex extraction process of Ti6Al4V and difficulty in melting, the cost is high, and it is difficult to process with traditional methods. ${ }^{22-24}$ The great advantage of $\mathrm{AM}$ is reducing the process chains, increasing the efficiency, and avoiding material waste during the process of producing near-net-shape components with complex geometries so that the costs is significantly reduced..$^{25-27}$ Thereby, many manufacturers process Ti6Al4V powder through SLM to make complex parts for aerospace and biomedical devices. However, the parts produced by SLM technology cannot be used directly due to their high surface roughness, which restricts its development and potential high-end application. The Ra value of SLM parts usually changes from 10 to $30 \mu \mathrm{m}$, thus, affecting the dimensional precision, increasing friction, and destroying surface integrity. ${ }^{28,29}$ As is known, laser AM is a process of continuous melting and solidification, during which the materials change from powder to solid with the repeated heating and cooling. Actually, it is an unbalanced thermodynamic process. With the rapid melting and cooling rate, the phase transformation of the materials often occurs inside the parts, for example, the refined acicular $\alpha^{\prime}$ martensite, which appears in AM-fabricated Ti6Al4V alloy. During this process, residual stress also emerges at the same time, which can lead to deformation, cracking, and destroying the mechanical property of the parts. ${ }^{30-32}$ Therefore, it is necessary to postprocess the AM-fabricated Ti6Al4V alloy before using.

Conventional postprocessing methods, such as sandblasting, shot peening, chemical polishing, ultrasonic polishing, etc., are employed by many researchers. ${ }^{33-36}$ However, it is still hard to satisfy the manufacturer's demands because of time-consumption, less geometrical flexibility, and environmental pollution. For example, sand blasting can cause dust pollution and occupational diseases; the waste liquid in chemical polishing also causes water pollution. At the same time, it is difficult to obtain the ideal geometric tolerance and surface characteristics. While laser polishing is carried out in a closed space filled with argon, and the surplus powder can be sucked into the pipeline for recycling after printing, which has the advantages of less environmental pollution and high utilization rate of powder. The emergence of this technology resolves most of the problems posed by conventional techniques. Being ecofriendly, flexible, and highly efficient, laser polishing draws considerable attention of researchers for use in post-treatment of metallic AM components. ${ }^{37,38}$ More importantly, laser polishing can be completed on the same equipment as SLM. Thus, the processing environment is stable, the possibility of workpiece oxidation is reduced, and the integrated processing mode of SLM and postprocessing can be realized. However, compared with traditional postprocessing, laser polishing has certain limitations when polishing complex surfaces. It requires better equipment and more complicated program settings, which need in-depth research.

\section{Laser Polishing Mechanism}

Laser polishing is a process of rapid melting and solidification of a thin layer of metal surface that usually has tens to more than $100 \mu \mathrm{m}$. In laser polishing, the laser beam is precisely controlled to act on the surface of the workpiece, and the surface metal is melted under the action of the heat energy. The molten metal flows under surface tension and gravity, filling the concave parts and flattening the surface. During this period, the molten metal evaporates less, so there is almost no material loss in the laser polishing process. ${ }^{39-41}$ The diagram of laser polishing is shown in Fig. $1 .^{42}$ There are currently two forms of laser polishing. One is to fix the printed parts on a numerically controlled X-Y-Z stage and then perform polishing. This is laser polishing after AM and is performed separately. The other is that, when the printing is completed, the sample is not taken out of the chamber, and the surface of the workpiece is directly rescanned to achieve the purpose of polishing using laser processing parameters that are different from the printing. This is called in-situ polishing.

There exist two regimes in laser polishing, surface shallow melting (SSM) and surface overmelting (SOM).$^{43}$ Each mechanism is related to laser power and scanning speed. When the laser energy is not very large or the scanning speed is fast enough, only a short depth of surface melts. The melted layer thickness is less than the distance of peak-valley. The molten peak then flows 


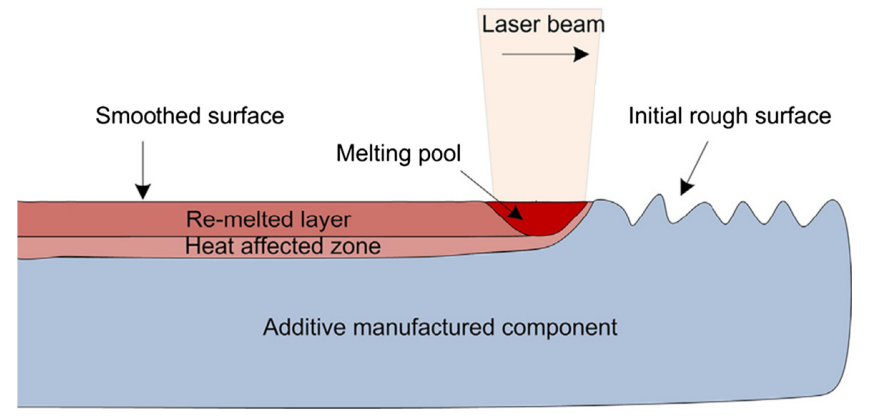

Fig. 1 Diagram of laser polishing. ${ }^{42}$

into a valley under the influence of liquid surface tension and gravity; thus, the distance of peak-valley becomes smaller. This situation is called SSM, or "a partially melted metal surface, ${ }^{44}$ and it can decrease the surface roughness to a certain extent. On the other hand, with the increasing of laser power or slowing of the scanning speed, the intensity of the laser beam increases further and not only the cap but also the whole particle is melted; the depth of the melted layer goes beyond the valley and then forms a molten pool, which results in the SOM regime. During the mechanism of SOM, because of the existence of the thermal gradient between the molten zone and the solidification front, the molten material is pulled away toward the solidifying front, and the surface waves appear, as shown in Fig. $2 .{ }^{45}$ Therefore, the surface roughness of parts under this situation will be higher than that of SSM. However, which regimes dominate the process of laser polishing? In fact, only when SSM and SOM are combined can laser polishing achieve the most perfect result. ${ }^{43,46}$ According to these two melting methods, the entire laser polishing process can be divided into coarse polishing (based on the SOM mechanism) and delicate polishing (based on the SSM mechanism). Yung et al. ${ }^{47}$ combined the two mechanisms to carry out coarse and delicate polishing for tool steel, that is, polishing the same workpiece twice. The results showed that the roughness decreased from the original 12 to $0.7 \mu \mathrm{m}$. The optimal combination parameters of coarse and delicate polishing are power of $200 \mathrm{~W}$, scanning speed of $508 \mathrm{~mm} / \mathrm{s}$, and scanning spacing of $0.127 \mathrm{~mm}$ and power of $100 \mathrm{~W}$, scanning speed of $1016 \mathrm{~mm} / \mathrm{s}$, and scanning spacing of $0.508 \mathrm{~mm}$, respectively. In the final analysis, the difference between the two mechanisms (SSM and SOM) lies in the difference in laser energy density. When the energy density is high, the melting layer is thicker, which is considered SOM. However, when the energy density is small, the shallow layer melting of the workpiece is called SSM. The energy density can be adjusted by changing the laser power and scanning speed; the expression is as follows:

$$
E=\frac{P}{D \cdot V}
$$

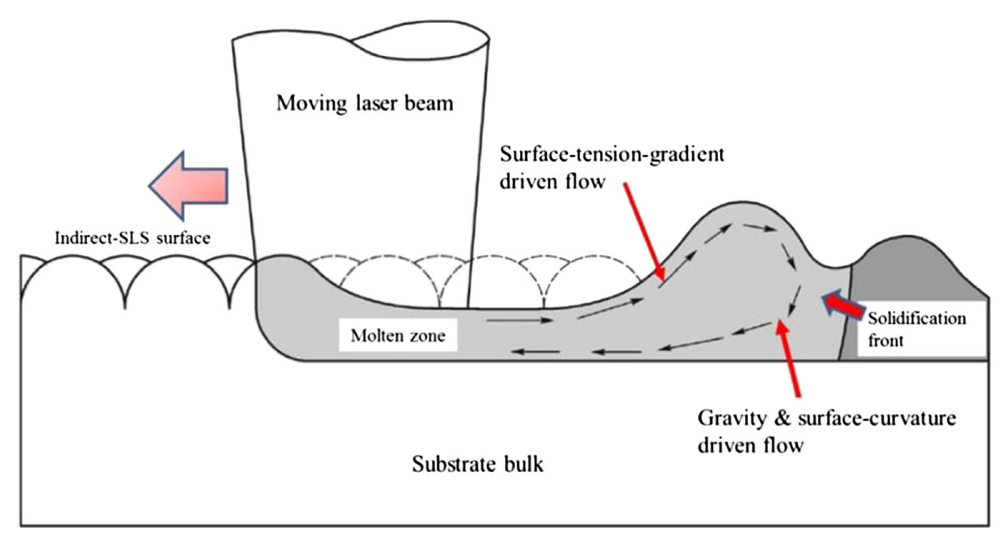

Fig. 2 The ripple shape during SOM. ${ }^{45}$ 
where $E$ is the energy density $\left(\mathrm{J} / \mathrm{mm}^{2}\right), P$ is the laser power $(\mathrm{W}), V$ is the scanning speed $(\mathrm{mm} / \mathrm{s})$, and $D$ is the laser spot diameter(mm).

\section{Surface Characterization of Laser Polishing Ti6Al4V}

\subsection{Surface Morphology and Roughness}

There are many factors affecting the surface morphology and roughness of laser polishing Ti6Al4V. The main factors depend on the choice of process parameters. To obtain a high precision machined surface, it is necessary to optimize the process parameters. Liang et al. ${ }^{12}$ and Zhou et al.$^{48}$ experimentally studied the relationship between the laser polishing process parameters of Ti6Al4V alloy and the surface quality and finally obtained the optimal combination of process parameters. Table 1 summarizes the surface roughness of laser polished Ti6Al4V alloy and lists the optimum process parameters corresponding to the surface roughness. It can be seen that the ultimate surface roughness after laser polishing can reach $0.3 \mu \mathrm{m}$, which is a $95 \%$ improvement compared with the roughness of as-received component.

In the laser polishing process, the process parameters directly affect the temperature gradient, which has a great influence on the roughness of laser polished parts. Therefore, the surface with the highest precision can be machined by the optimized process parameters. Liang et al. ${ }^{12}$ studied the influence of three different laser power densities $\left(0.853 \times 10^{5}, 1.703 \times 10^{5}\right.$, and $2.503 \times 10^{5} \mathrm{w} / \mathrm{cm}^{2}$ ) on the surface roughness of polished workpiece and found that the Ra value at $1.703 \times 10^{5} \mathrm{w} / \mathrm{cm}^{2}$ was the minimum, reaching $2.1 \mu \mathrm{m}$. With the increase of power density $\left(2.503 \times 10^{5} \mathrm{w} / \mathrm{cm}^{2}\right)$, surface roughness increased. Further analysis showed that it was the SSM regime when the power density was $0.853 \times 10^{5}$ and $1.703 \times 10^{5} \mathrm{w} / \mathrm{cm}^{2}$. With the increase of power density $\left(2.503 \times 10^{5} \mathrm{w} / \mathrm{cm}^{2}\right)$, the temperature of the workpiece increases, and the depth of the molten pool exceeds the peak-valley value, which is the SOM regime. At the same time, Ti6Al4V has a negative temperature coefficient of surface tension, that is, the surface tension of molten metal decreases with increasing temperature. The temperature in the center of the molten pool is the highest, and the temperature at the edge of the molten pool is lower. Therefore, the distribution of surface tension gradually increases from the center of molten pool to the edge of molten pool, forming the surface tension gradient. The molten liquid is pulled to the solidification front (the edge of the molten pool) under the action of the surface tension gradient, ${ }^{53}$ causing a height difference in the liquid level. Under gravity, the molten liquid flows back again, forming a ripple, as shown in Fig. 2, and resulting in an increase in surface roughness.

Table 1 Surface roughness and the corresponding process parameters of laser polishing Ti6Al4V.

\begin{tabular}{|c|c|c|c|c|c|c|}
\hline Laser & $\mathrm{PD}\left(\mathrm{w} / \mathrm{cm}^{2}\right)$ & $\mathrm{SS}(\mathrm{mm} / \mathrm{s})$ & $\mathrm{SD}(\mu \mathrm{m})$ & $\mathrm{IR}(\mu \mathrm{m})$ & $\mathrm{R}(\mu \mathrm{m})$ & Reference \\
\hline Nanosecond pulsed fiber laser & $1.7 \times 10^{5}$ & 3750 & 150 & Ra10.2 & Ra2.1 & 12 \\
\hline Nanosecond pulsed fiber laser & $1.2 \times 10^{7}$ & 200 & 44 & Sa5.2 & $\mathrm{Sa0.4}$ & 38 \\
\hline Nanosecond pulsed laser & $2.3 \times 10^{5}$ & 300 & 130 & Sa5.0 & Sa2.8 & 49 \\
\hline Continuous wave fiber laser & $9.7 \times 10^{3}$ & 30 & 1400 & Ra7.3 & $\mathrm{Ra} 0.6$ & 48 \\
\hline Continuous wave fiber laser & $5.1 \times 10^{6}$ & 500 & 100 & Sa8.8 & Sa3.3 & 50 \\
\hline Continuous wave fiber laser & $8.2 \times 10^{4}$ & 12.5 & 500 & Ra10.2 & $\mathrm{Ra} 2.4$ & 51 \\
\hline Continuous wave fiber laser & $4.6 \times 10^{6}$ & 150 & 50 & Ra6.5 & $\mathrm{Ra} 0.3$ & 52 \\
\hline Fiber laser & $8.0 \times 10^{4}$ & 5 & 400 & Sa21.5 & Sa0.5 & 42 \\
\hline
\end{tabular}

Note: PD, power density; SS, scanning speed; SD, spot diameter; IR, initial roughness; R, roughness after laser polishing. 
The effect of laser power density on the surface roughness of components has been generally accepted. Similarly, the combination of scanning speed and laser power is also very crucial to the roughness of laser polished titanium alloy. Zhou et al ${ }^{48}$ investigated the effect of scanning speed and laser power on the surface roughness of Ti6Al4V alloy after laser polishing by the orthogonal test. It was found that the minimal roughness $(0.56 \mu \mathrm{m})$ was acquired at higher power $(150 \mathrm{w})$ and high scanning speed $(30 \mathrm{~mm} / \mathrm{s})$. This finding is very similar to that of Jaritngam et al. ${ }^{49}$ The surface roughness decreases slightly with the increase of scanning speed and power. Generally speaking, the increase or decrease of the surface roughness is related to the heat input and laser-material interaction time. Higher laser power results in sufficient heat input, and the high scanning speed avoids overmelting caused by long interaction time, thus ensuring the SSM regime. Then, the surface roughness of laser polished Ti6Al4V alloy is reduced. If low power and low scanning speed are used, the long-time laser-material interaction can also ensure sufficient heat input, but the processing efficiency is greatly reduced.

In addition to the selection of process parameters, the influence of other factors on the surface roughness of laser-polished Ti6Al4V alloy should also be taken into account. Tian et al. ${ }^{42}$ measured the surface roughness of laser-polished Ti6Al4V using a Nanofocus $\mu$ Scan laser profilometer and a white light interferometer with different resolutions and found that the Sa parameter was reduced from as-received 21.46 to $5.5 \mu \mathrm{m}$ and $0.51 \mu \mathrm{m}$, respectively. The difference in the measurement results was mainly due to the size of the sampling area, namely, $2 \mathrm{~mm} \times 3 \mathrm{~mm}$ and $0.13 \mathrm{~mm} \times 0.17 \mathrm{~mm}$. The small sampling area was similar to the $\beta$ grain size, and it revealed that the roughness after laser polishing was related to surface relief between individual grains and grain boundary grooving generated during the solidification process. The surface morphology is shown in Fig. 3. Zhang et al. ${ }^{50}$ studied the in-situ polishing of additive manufactured Ti6Al4V with a fiber laser. There was no need to clamp the components twice after 3D printing. It was the same as that of the printing processing environment and almost no oxidation occurred.
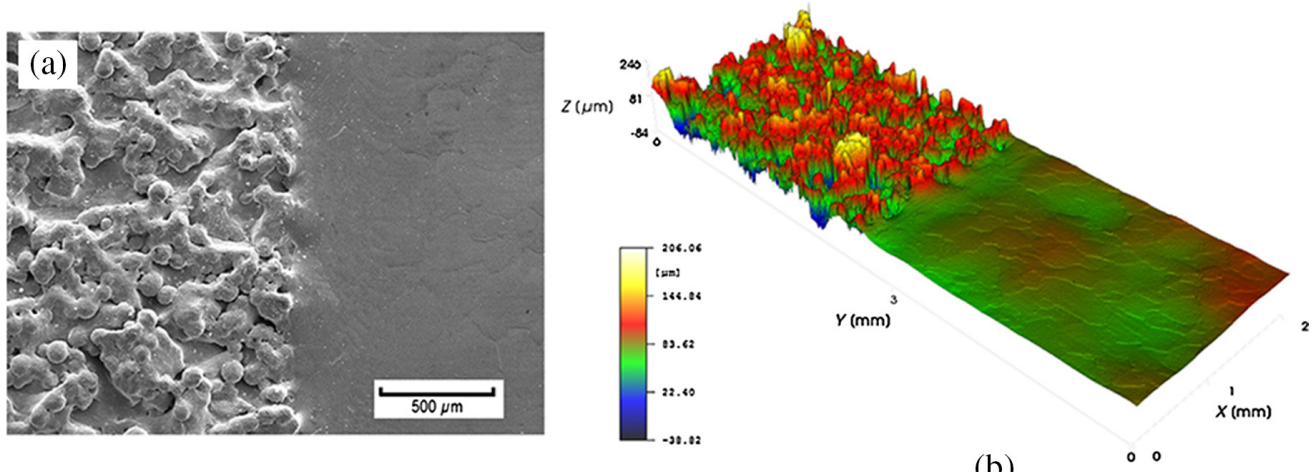

(b)

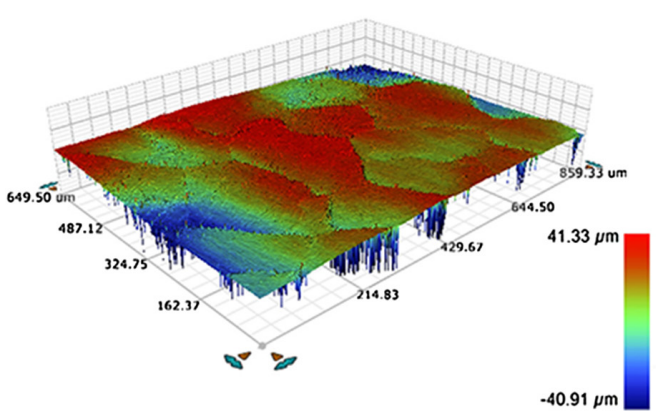

(c)

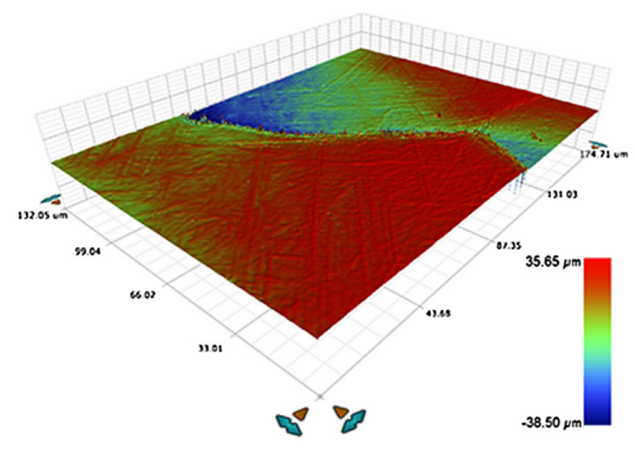

(d)

Fig. 3 Roughness reduction by laser polishing measured by surface profiling at different scales: (a) an SEM image showing the contrast between the original and polished surfaces; (b) the equivalent transition using the laser profilometer, with an area of $2 \mathrm{~mm} \times 6 \mathrm{~mm}$; (c) the LP surface measured over a $0.6 \mathrm{~mm} \times 0.86 \mathrm{~mm}$ area; and (d) measured over a $0.13 \mathrm{~mm} \times 0.17 \mathrm{~mm}$ area by white light interferometery. ${ }^{42}$ 
The results showed that surface roughness Sa was $3.32 \mu \mathrm{m}$ after polishing when the laser power was $400 \mathrm{~W}$ and the feed rate was $0.5 \mathrm{~m} / \mathrm{s}$.

In a word, the surface morphology and roughness are related to numerous factors. Besides the process parameters such as laser power density and scanning speed, there are the initial surface roughness of metal, homogeneity of the material, thermos-physical properties, and so on. These factors affect the polishing results to varying degrees. There are still many challenges in the surface finish of laser polishing, so tremendous efforts are needed to satisfy the requirements of titanium alloy in the aerospace, marine, and biomedical fields.

\subsection{Microstructure}

The microstructure changes of Ti6Al4V alloy after laser polishing are usually shown in five aspects: surface oxidation, microcracks, recast thickness, phase change, and heat-affected zone depth. The above changes are closely related to heat input. During the process of laser irradiation, the temperature of the workpiece ascends gradually, and the heat accumulation is sufficient with the increase of heat input, leading to the thickening of the recast layer and the deepening of the heat-affected area. Jaritngam et al ${ }^{49}$ studied the effects of different laser powers and scanning speeds on the thickness of the recast layer and the depth of the heat-affected zone. It was found that when the power was $30 \mathrm{~W}$ and the scanning speed was $50 \mathrm{~mm} / \mathrm{s}$, the thickest recast layer was $70 \mu \mathrm{m}$, and the deepest heat affected zone was $262 \mu \mathrm{m}$. When the original surface roughness of workpiece was larger, the lower the scanning speed was, the thicker the recast layer would be under the same laser power. This is because the rougher the surface is, the higher the absorption of light is. However, the depth of the heat-affected area was independent of the original roughness. When the laser power was the same, the lower the scanning speed was, the deeper the heataffected area was, as shown in Fig. 4. Furthermore, the thick and brittle recast layer was prone to crack under the action of high thermal stress. On the contrary, the crack is not obvious when using low power (10 and $20 \mathrm{w}$ ), as shown in Fig. 5. In short, the thickness of the recast layer and the depth of the heat-affected zone are related to the heat input. The more heat input, the more heat accumulation, the thicker the recast layer, and the deeper the heat-affected zone. This causes microcracks on the surface and subsurface. Based on the premise of ensuring the surface roughness, we can appropriately increase the scanning speed, reduce the laser power, or increase the repetition frequency to reduce the heat input to alleviate the thermal damage.

After laser polishing, the chemical composition of the Ti6Al4V alloy surface also changed. Vaithilingam et al. ${ }^{54}$ analyzed the effect of laser remelting on surface chemistry of AM Ti6Al4V alloy and found the oxide film on the remelted surface was rich in aluminum, while the nonremelted surface was rich in titanium. The oxide layer of the remelting surface was thicker than that of the nonremelting surface. Generally speaking, the corrosion resistance of parts is directly proportional to the thickness of the oxide layer. However, the concentration of $\mathrm{Al}$ increases

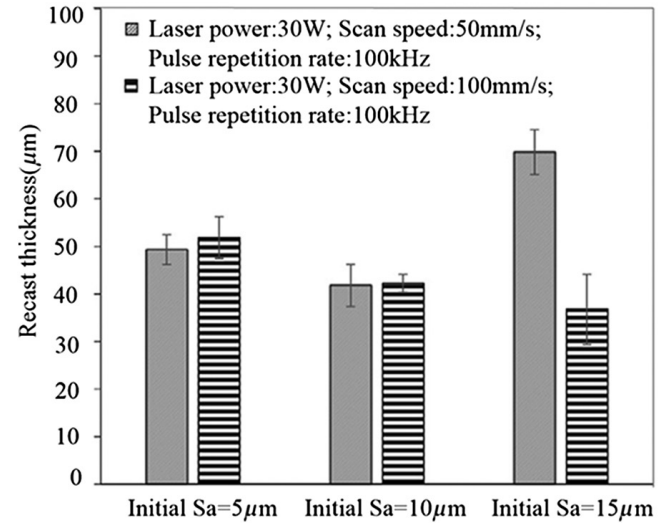

(a)

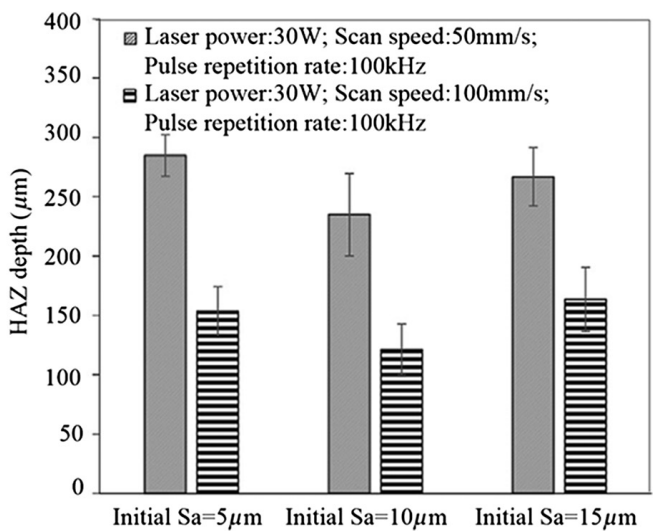

(b)

Fig. 4 (a) Thickness of recast layer and (b) depth of heat-affected zone induced by the different laser polishing conditions and initial surface roughness. ${ }^{49}$ 


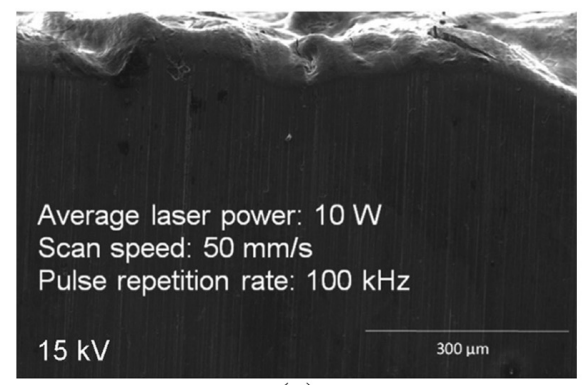

(a)

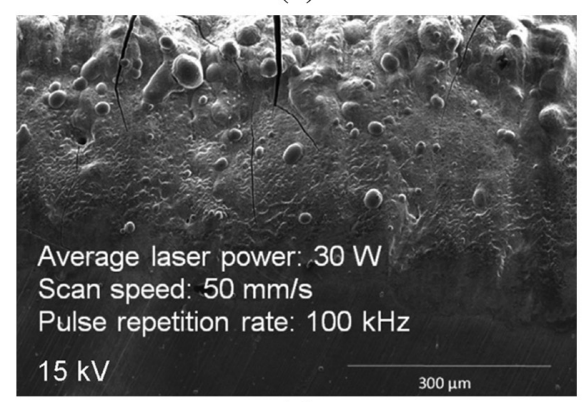

(c)

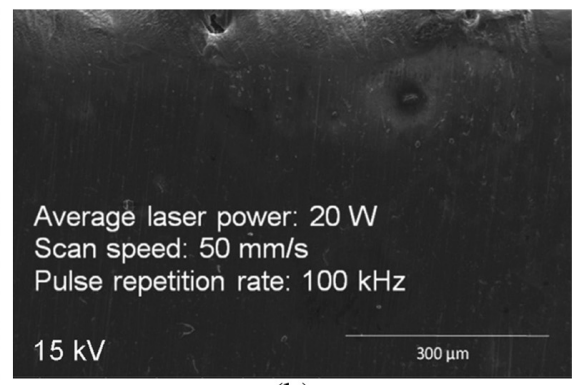

(b)

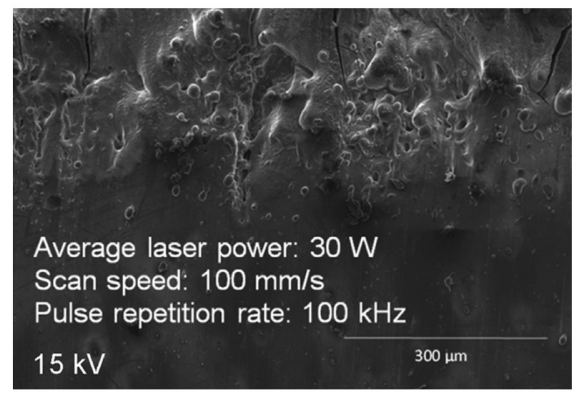

(d)

Fig. 5 Subsurface of laser-polished region obtained under the different processing conditions. ${ }^{49}$

during rapid solidification because the solubility of $\mathrm{Al}$ in $\mathrm{Ti}$ is very low when the temperature reaches $500^{\circ} \mathrm{C}$ to $600^{\circ} \mathrm{C}$ and $\mathrm{Ti}_{3} \mathrm{Al}$ phase precipitates. When the heat input is higher, such as through decreasing the scanning speed, the material maintains a high temperature for a relatively long time and promote further precipitation. The high concentration of aluminum would affect the corrosion resistance of the workpiece. Therefore, the scanning speed and laser power should be properly controlled to avoid excessive heat input. On the other hand, the formation of the acicular $\alpha^{\prime}$ martensite phase after laser remelting also resulted in poor corrosion resistance of the component. Zhou et al. ${ }^{48}$ optimized the process parameters through 16 groups of orthogonal experiments and obtained the lowest average roughness of workpiece of $0.56 \mu \mathrm{m}$ when the power was $150 \mathrm{~W}$, the scanning speed was $30 \mathrm{~mm} / \mathrm{s}$, and the spot overlap rate was $92 \%$. Through electrochemical experiments, it is found that the corrosion resistance of parts after laser polishing is improved. The main reason is that the large peak valley value accelerates the corrosion when the surface of Ti6Al4V alloy is rough, while the surface roughness is small after laser polishing. Hence, the corrosion resistance is enhanced. In addition, the grain sizes also affect the corrosion resistance. The corrosion rate of fine grains is faster than that of coarse grains. Accordingly, the grain size in the polishing zone of Ti6Al4V alloy becomes larger after polishing, as shown in Fig. 6. In short, the change of microstructure such as chemical composition and grain size will affect the properties of materials, so it is necessary to optimize the process parameters to process the parts that meet the requirements.

Another significant change of microstructure after laser polishing is phase transformation. Ti6Al4V is an $\alpha+\beta$ dual-phase Ti alloy, where $\mathrm{Al}$ is an $\alpha$ phase stabilizer, which can increase the phase transition temperature, and $\mathrm{V}$ is a $\beta$ phase stabilizer, which can reduce the $\beta$ phase transition temperature. During laser polishing, as the temperature rises to the beginning of the transition, the phase transition $\alpha \rightarrow \beta$ occurs. When it exceeds the transition temperature (about $1273 \mathrm{~K}$ ), the $\alpha+\beta$ phase is almost completely transformed into the $\beta$ phase. As the laser beam leaves, the temperature decreases, and the surface of workpiece cools rapidly. Its cooling rate $\left(1.209 \times 10^{4} \mathrm{k} / \mathrm{s}\right)$ far exceeds the critical cooling rate $(410 \mathrm{k} / \mathrm{s})$, and the $\beta$ phase finally transforms into a needle-like $\alpha$ ' Martensite phase. Ma et al.$^{38}$ verified this phase transition process by SEM observation and XRD analysis before and after laser polishing, and the results are shown in Fig. 7. However, Marimuthu et al. ${ }^{51}$ had different opinions. He found through experiments that the columnar microstructure before and after laser polishing did not change much, mainly due to the similar cooling rate of powder particles during AM and laser polishing. Furthermore, he pointed out that the formation of the $\alpha$ phase could be explained by the oxygen concentration 


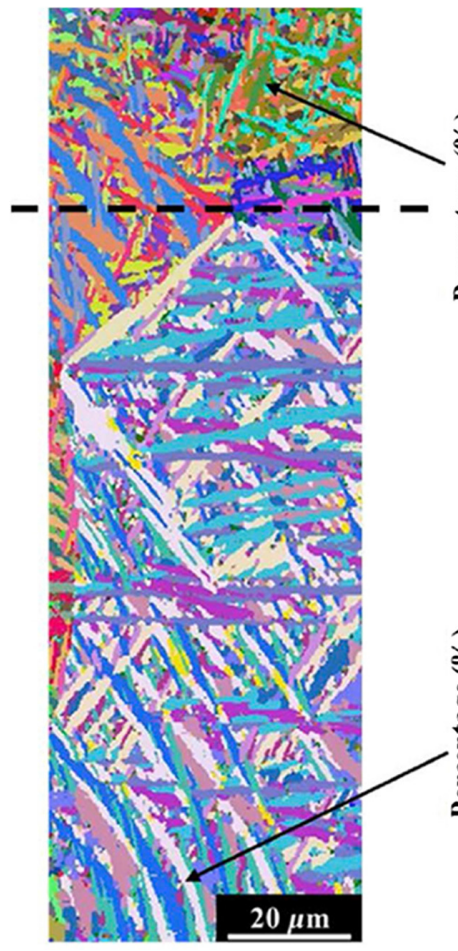

all Euler

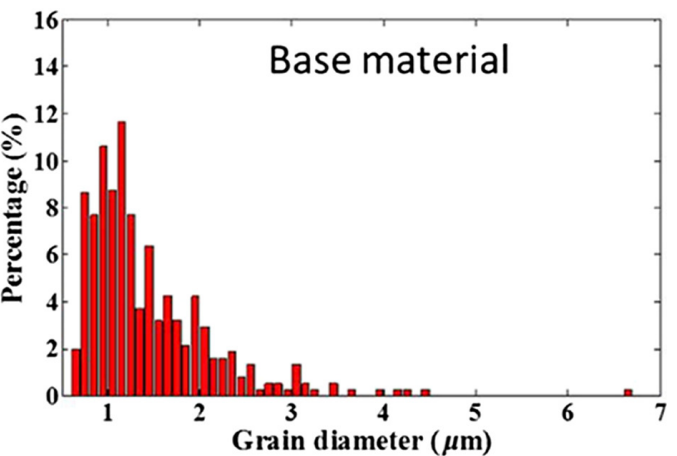

Average grain size $1.43 \mu \mathrm{m}$

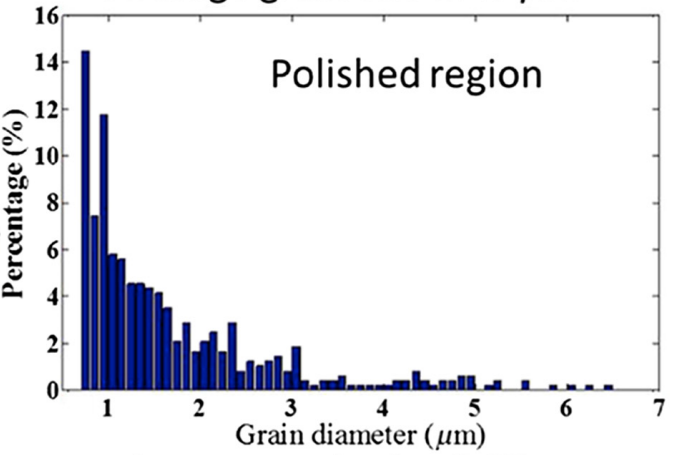

Average grain size $1.69 \mu \mathrm{m}$

Fig. 6 Electron backscatter diffraction (EBSD) results and grain size. ${ }^{48}$

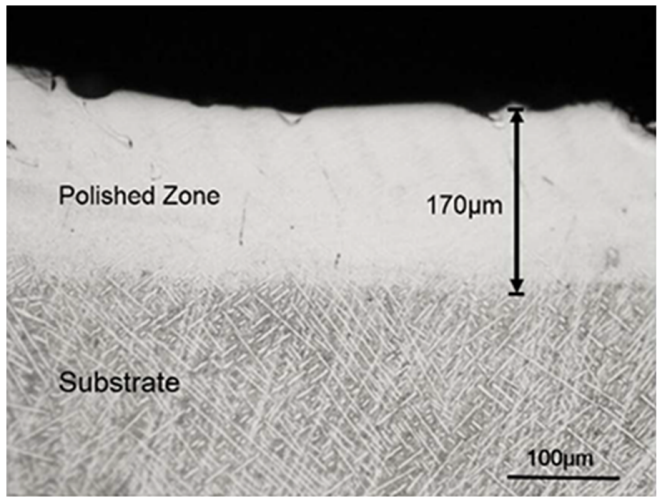

(a)

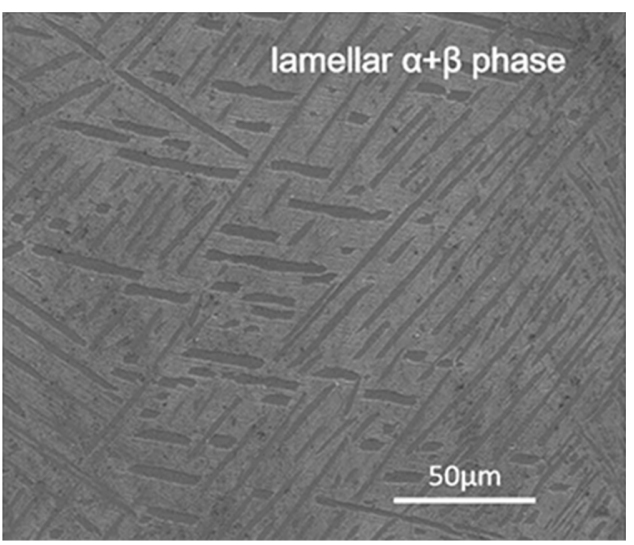

(c)

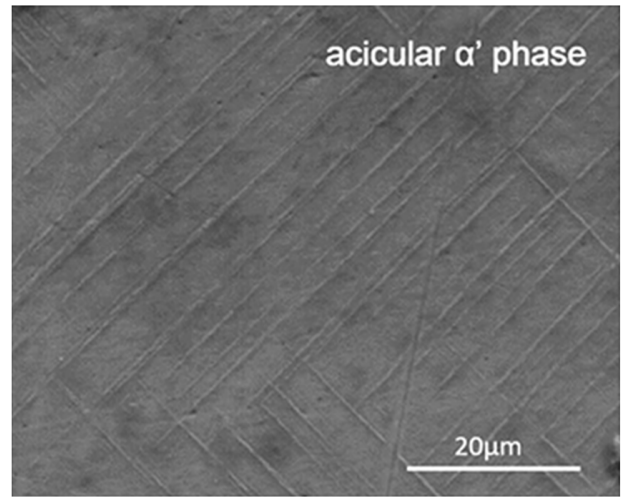

(b)

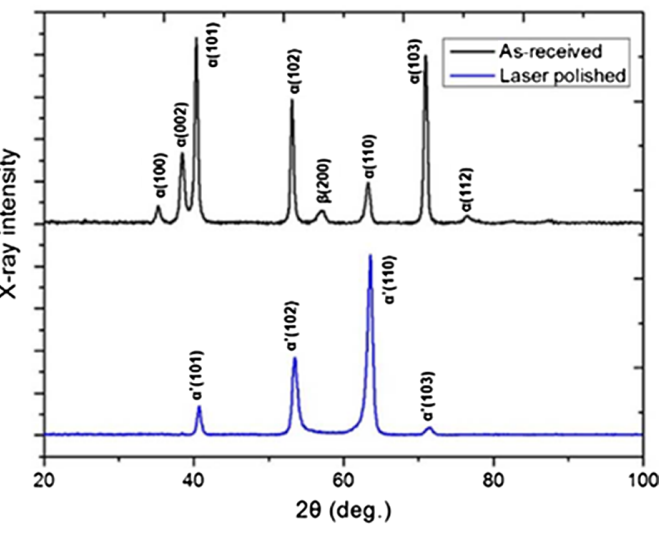

(d)

Fig. 7 Microstructure analysis of laser-polished TC4 surface: (a) overview, (b) microstructure of polished zone, (c) microstructure of substrate, and (d) XRD profiles. ${ }^{38}$ 
and material hardness before and after laser polishing. But, experimental results showed that maximum oxygen concentration was $<10 \%$, which was similar to that before polishing, and the microhardness of the substrate and polished zone were $380 \mathrm{HV}$ and $420 \mathrm{HV}$, respectively, which was not much different, so it revealed that there was no $\alpha$ phase and no change to the subsurface characteristic.

In general, the different research results are due to the different lasers selected, the processing parameters being distinct, the heat absorbed by the workpiece being also not alike, and the changes in the microstructure being diverse. Oxidation during the polishing process is inevitable, but further study on the thickness and chemical composition of the oxide layer will help to improve the understanding. Phase transition can easily cause changes in mechanical properties and should be slowed down as much as possible. However, since the melting temperature (1923 k) exceeds the transformation temperature (1273 k), the first stage of phase transition $(\alpha+\beta \rightarrow \beta)$ is inevitable. The formation of secondary acicular Martensite $\left(\alpha^{\prime}\right)$ occurs in the cooling period. The cooling rate can be reduced by adding thermal insulation materials to slow down the phase transformation in the second stage. In a word, surface oxidation, microcracks, recast layer thickness, and heat-affected zone depth are all related to each other, and heat input is a key factor affecting surface quality and subsurface damage. Therefore, laser polishing of Ti6Al4V should be further optimized to improve surface quality and mechanical property, while minimizing thermal damage and other defects. The combination of multiobjective optimization and the Taguchi experiment can determine the best processing conditions based on the relevant response.

\section{Mechanical Property of Laser Polishing Ti6Al4V}

\subsection{Microhardness}

The microhardness of additive manufactured Ti6Al4V alloy after laser polishing is one of the important mechanical properties. The cross-section of the titanium alloy after laser polishing is divided into three areas: the remelting area, the heat-affected zone, and the substrate layer. Compared with the base layer, the microhardness of the remelting area is significantly increased, while the hardness of the heat-affected zone is increased less. There are three main reasons for the increase in hardness of the polishing layer. First, $\alpha^{\prime}$ Martensite phase, which has a hexagonal close-packed structure, is formed and the bulk modulus is higher than for the $\alpha$ and $\beta$ phases in the original material, so the hardness increases. Second, the martensite phase has a high dislocation density and a large number of phase boundaries in a double-needle structure. It has an effect of fine grain strengthening and increases the surface hardness. Finally, the reduced porosity in the laser-polished layer increases the hardness and density of the material. Many articles $^{12,48,52}$ have similar reports. Li et al. ${ }^{52}$ found that the microhardness was $426 \mathrm{HV}$, which was about $25 \%$ higher than the as-received sample $(340 \mathrm{HV})$, as shown in Fig. 8. The increase of the hardness also improves the wear resistance of the Ti6Al4V alloy. The wear scar of the laser

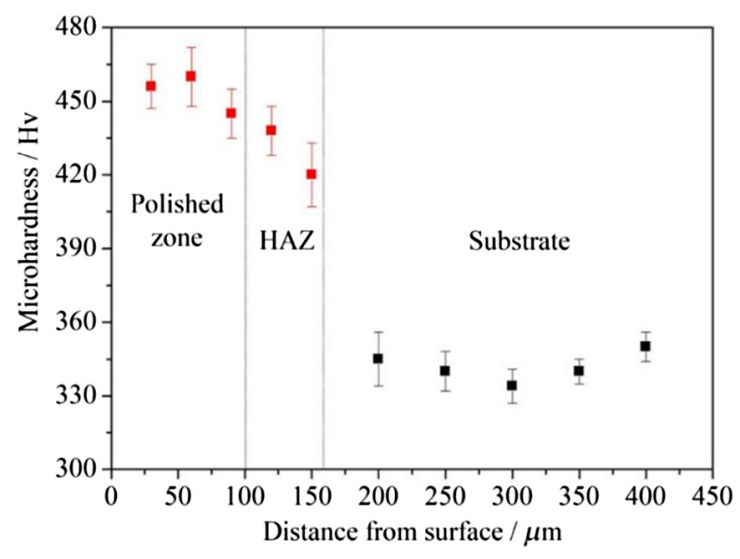

Fig. 8 Microhardness distributions in the laser-polished layer. ${ }^{52}$ 
polished surface is shallower than the as-received sample, and the wear rate is $39 \%$ lower than the original parts after calculation.

\subsection{Residual Stress and Fatigue Life}

In the laser polishing of additive manufactured Ti6Al4V alloy, rapid melting and solidification make laser polishing an uneven thermodynamic process, which is prone to residual stress on the polished surface. Residual stress affects the propagation of the fatigue cracks and has an important impact on the fatigue life of parts. There are many ways to measure residual stress, for example, groove cutting, x-ray diffraction, ion beam milling, and laser line scanning profiling. These methods can obtain the residual stress distribution of the polished area. Tian et al. ${ }^{42}$ used the $\sin (2 \theta)$ method by $\mathrm{x}$-ray diffraction to measure the magnitude of residual stress generated during laser polishing. The results showed that there was a residual tensile stress of $580 \mathrm{MPa}$ parallel to the scanning direction after laser polishing, while the residual stress in the vertical direction was $325 \mathrm{MPa}$. However, the residual stress disappeared at a depth of $1 \mathrm{~mm}$ from the surface. This was because the surface of the cold substrate was heated by a small moving heat source during the polishing process. The thermal stress relaxation caused by the local volume expansion under the heat source caused a compressive plastic mismatch. After the laser beam left, the material temperature decreased and the workpiece hardened, so the tensile stress was difficult to release. There was a thermal field elongation characteristic in the direction of heat source travel, so the residual stress parallel to the scanning direction was greater.

Under the action of alternating loads, fatigue failure of AM parts often occurs at cracks and warpage. After laser polishing, the defects are greatly improved, but the fatigue characteristics of the workpiece are still crucial. The fatigue performance of laser polished parts is mainly affected by microstructures, residual stress, and internal defects such as holes and microcracks. Li et al. ${ }^{52}$ studied the fatigue life of Ti6Al4V alloy before and after laser polishing and found that, compared with the as-received parts, the fatigue life of laser polished specimens decreased to $10^{4}$ to $10^{5}$ from $10^{7}$ cycles, as shown in Fig. 9(b). One of the reasons is that the formation of the $\alpha^{\prime}$ martensite phase makes the surface of the workpiece hard and brittle. Such a surface has a high notch sensitivity, which is prone to cracking and weakens the fatigue characteristics of the parts. After laser polishing, the elongation decreased by $5 \%$, but the tensile strength and yield strength

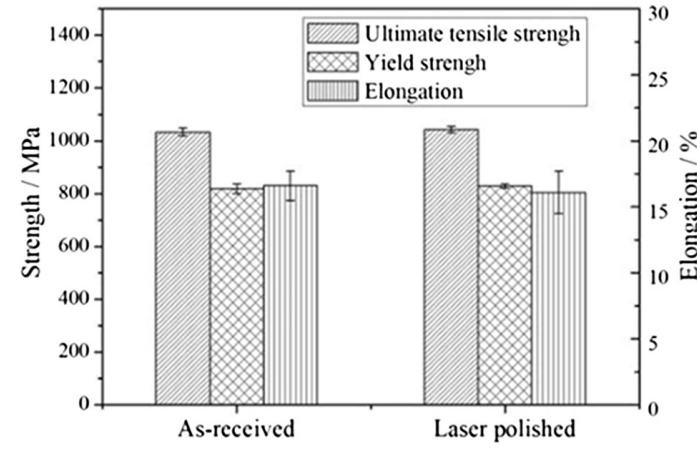

(a)

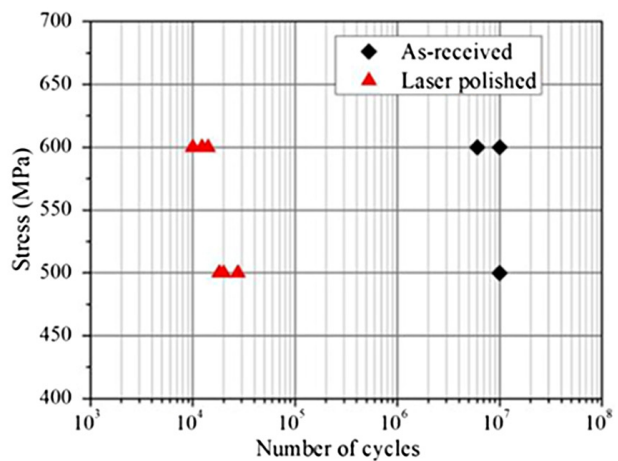

(b)

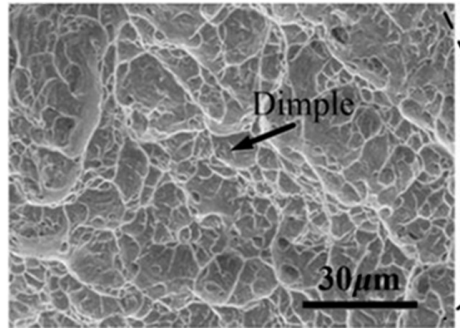

(c)

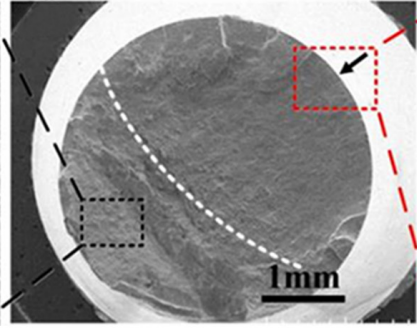

(d)

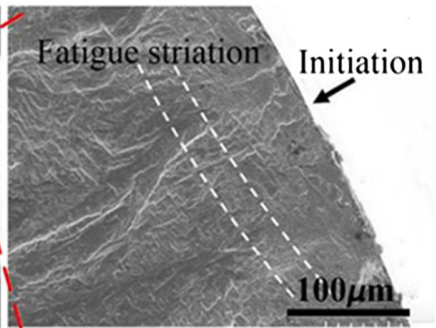

(e)

Fig. 9 (a) Tensile properties, (b) high cycle fatigue life, (c) dimples due to overload in (d), (d) overview of fracture surface, and (e) crack initiation area at the laser polished surface in (d). ${ }^{52}$ 
did not change much, as shown in Fig. 9(a). The residual tensile stress that occurs during laser polishing also accelerates fatigue fracture. Crack initiation occurs at the pores of the polished area and then propagates under the effect of residual stress, as shown in Fig. 9(e), finally resulting in a transient rupture zone with a pit shape, as shown in Fig. 9(c). This is a typical ductile fracture characteristic, indicating that the substrate has good ductility. In addition, the internal defects of the parts will also shorten the fatigue life. Therefore, the top priority for the next step is to reduce the residual stress and defects of additive manufacture, as well as suppressing the transformation of phase.

Heat treatment is one of the main post-treatment methods for changing the residual stress. Leuders et al. ${ }^{55}$ used three methods to heat treat SLM Ti6A14V, namely $800^{\circ} \mathrm{C}$ (below $\beta$-transus) under Argon atmosphere, $1050^{\circ} \mathrm{C}$ (above $\beta$-transus) in evacuated quartz glass tubes, and hot isostatically pressed (HIP) at $920^{\circ} \mathrm{C}$ at a pressure of 1000 bar for $2 \mathrm{~h}$. The results showed that the residual stress on the surface of the workpiece was greatly reduced after $800^{\circ} \mathrm{C}$ heat treatment, especially in the $y$ direction, from the original 235 to $10 \mathrm{MPa}$. The reduction of residual stress helped to slow down the growth of fatigue cracks. After heat treatment at $1050^{\circ} \mathrm{C}$, the size of the $\alpha$ phase and the volume fraction of the $\beta$ phase increased, which enhanced the toughness of Ti6Al4V. The porosity of the workpiece decreased to the lowest after HIP, and the porosity was one of the main reasons for the fatigue crack initiation and fatigue strength reduction. Therefore, the heat treatment not only reduced the residual stress but also increased the fatigue life of the parts. On the other hand, when the stress of the part is large enough to cause plastic deformation or fracture of the material, the post-treatment hardly works. Therefore, the real-time stress control is also very important. The on-line thermal state detection of molten pool or temperature field can be realized by optical detection such as infrared imaging and high-speed x-ray imaging with an appropriate image algorithm. Through the closed-loop feedback control of the input laser energy, the surface temperature field is homogenized, the thermal gradient is reduced, and the residual stress is adjusted. ${ }^{56,57}$

\subsection{Simulation Analysis}

Numerical simulation provides a reference for experiments and is an indispensable part of much research. In the process of laser polishing, the finite element simulation method is often used to analyze the temperature field distribution, the depth and width of the molten pool, and the fluid flow speed. In general, the experimental outcomes are compared with the simulation results to verify the accuracy of the mold and experiment. Li et al. ${ }^{52}$ considered that the phase transformation process in the laser polishing area mainly depended on the temperature change and the cooling rate. Using the ABAQUS to simulate the temperature field distribution of the Ti6Al4V alloy during laser polishing according to the transient heat balance equation in the model, it was found that the temperature decreased from $2800^{\circ} \mathrm{C}$ in the melting zone to $1600^{\circ} \mathrm{C}$ in the heataffected zone. Then, the temperature field was compared with the cross-sectional view after laser polishing, as shown in Fig. 10, and the formation process of the needle-shaped $\alpha^{\prime}$ martensite phase was explained. The heat transfer mechanisms and the change of surface morphology (surface ripple) during laser polishing of Ti6Al4V alloy were studies by Marimuthu et al. ${ }^{51}$ It had been found that the width of the molten pool magnified with the increase of the laser power. When the power was $160 \mathrm{~W}$, the width reached the maximum $(0.41 \mathrm{~mm})$. As the laser power was further increased, the rate of increase in the width of molten pool decreased exponentially, but the thermal energy increased, which increased the velocity of the molten pool. Under the effect of negative surface tension coefficient, the melted material flowed outward from the center of molten pool, causing the center of the molten pool to swell and the boundary of the molten pool to sag, as shown in Fig. 11. Therefore, the high melt pool velocity made the surface morphology worse. On the other hand, Fig. 12 shows the change of the melt pool speed with the laser power. The surface tension gradient (Marangoni convection) was the main factor affecting the melt pool dynamics and convective fluid flow. At the same time, surface tension was a function of the temperature gradient in the melt pool, and it increases with decreasing temperature. The temperature of the center of the molten pool was the highest and the edge was lower, so the fluid flowed outward under the effect of tension, providing effective heat conduction from the center to the boundary. Ma et al. ${ }^{58}$ studied the relationship between the shape of molten pool and the profile of 


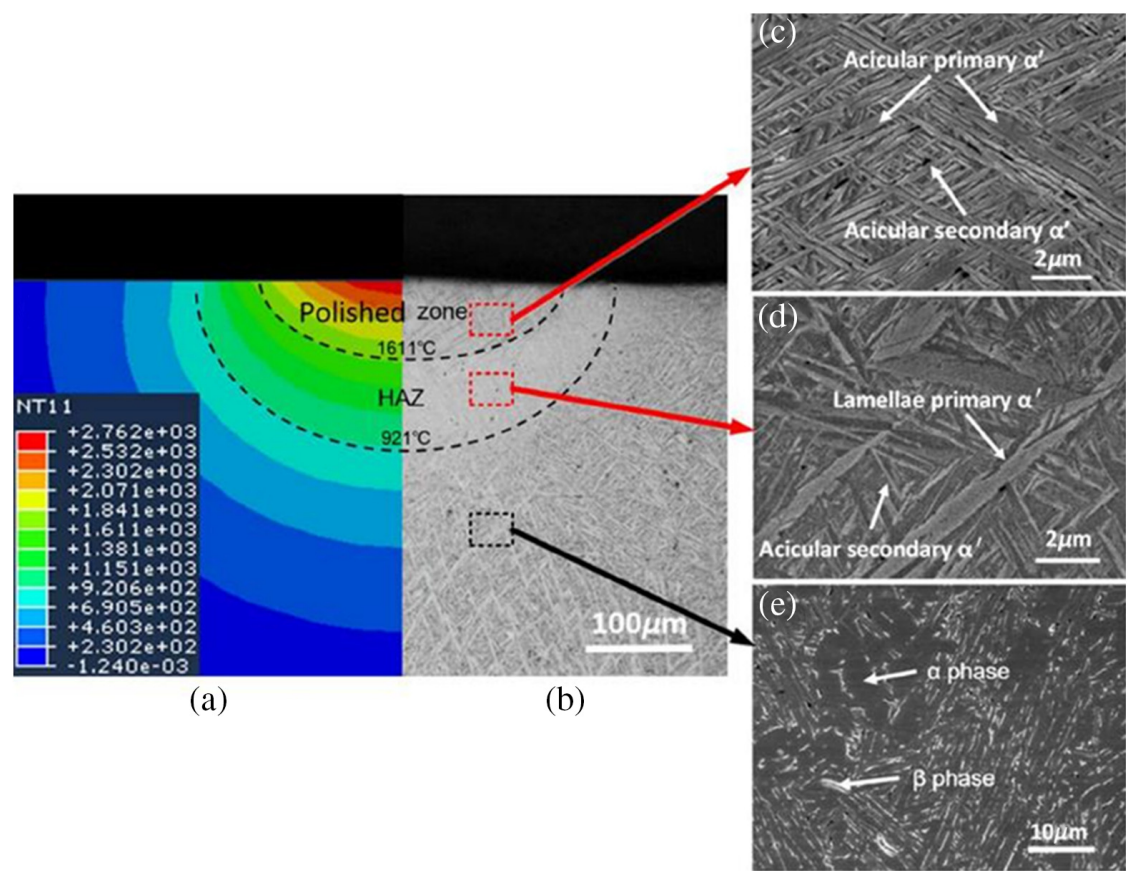

Fig. 10 (a) Temperature distribution of cross-section view, (b) microstructure, (c) polished zone, (d) heat-affected zone, and (e) as-received zone. ${ }^{52}$

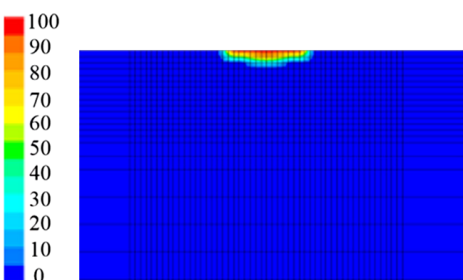

(a)

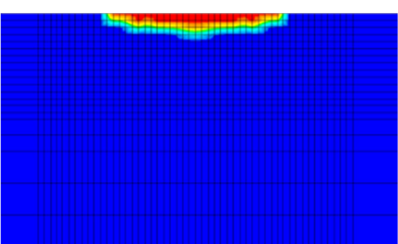

(b)

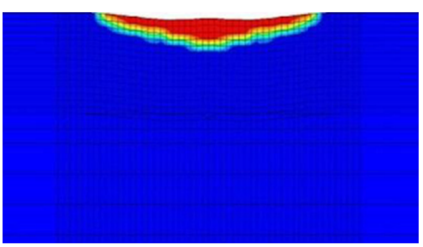

(c)

Fig. 11 Comparison of liquid fraction (\%) along the midpoint cross-section transverse to polishing direction, showing the change in surface topology of (a) $120 \mathrm{~W}$, (b) $160 \mathrm{~W}$, and (c) $200 \mathrm{~W}$, with a constant speed of $600 \mathrm{~mm} / \mathrm{min}^{51}$

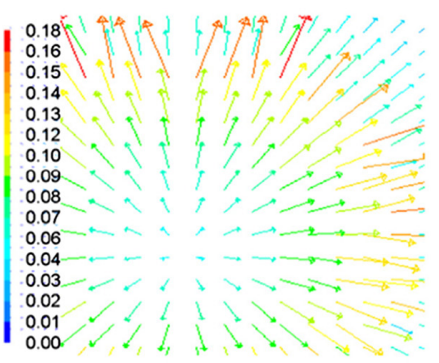

(a)

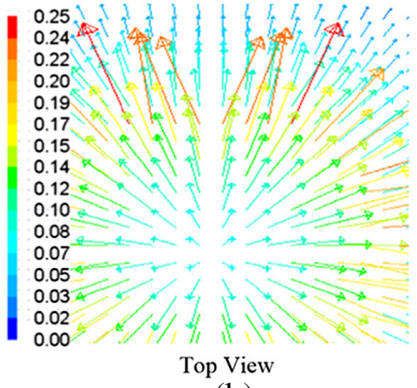

(b)

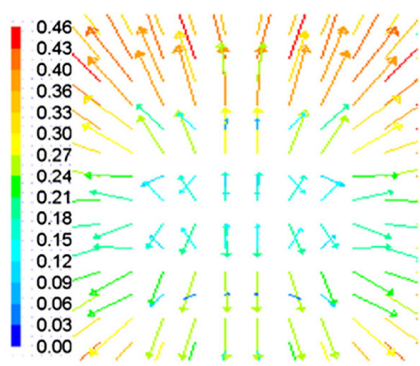

(c)

Fig. 12 Comparison of top surface velocity vector (m/s) for laser power of (a) $120 \mathrm{~W}$, (b) $160 \mathrm{~W}$, and (c) $200 \mathrm{~W}$, with a constant speed of $600 \mathrm{~mm} / \mathrm{min}^{51}$

the solidified surface and the laser pulse duration during the laser polishing of Ti6Al4V alloy through numerical simulation. The molten pool deepened with the prolongation of pulse duration. The peak-valley value (PVH) of the resolidified surface was normalized by the radius of the molten pool, and the normalized PVH changed when the pulse width was obtained, as shown in Fig. 13. This shows that the optimal pulse duration was $0.66 \mu$ s when the workpiece surface 


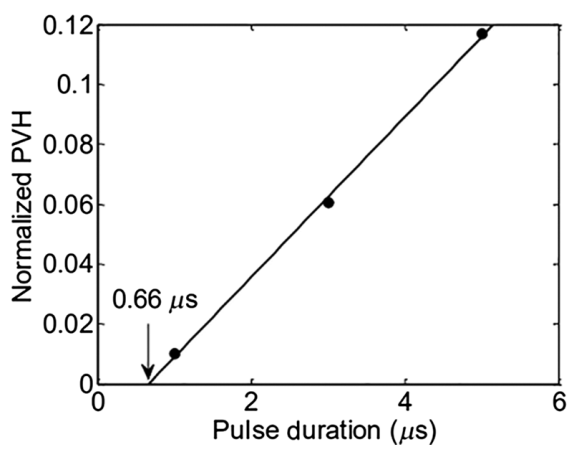

Fig. 13 The relationship between normalized $\mathrm{PVH}$ and pulse duration. ${ }^{58}$

reached the smoothest $(\mathrm{PVH}=0)$. There are also some references ${ }^{59-61}$ that have solved some problems in the experiment by simulating the laser polishing process. However, there are still few reports on numerical models, and that will be the next focus here.

\section{Summary}

Additive manufactured Ti6A14V alloy has excellent properties and great development potential, but the surface integrity after AM has become one of the difficulties restricting their engineering application. Laser polishing, as a post-treatment technique, can overcome the problems of surface roughness and cracks in the AM process and can eliminate the pores in the remelting layer. At the same time, the heat treatment after laser polishing can improve the density of the workpiece and reduce the residual stress. In this review, the laser polishing mechanism is analyzed and the surface morphology, microstructure, mechanical properties, and numerical simulation of titanium alloy after laser polishing are discussed. The process parameters of laser polishing (laser power, scanning speed, etc.) and the polishing environment can determine the microstructure and mechanical properties of AM Ti6Al4V alloy. Unreasonable selection of process parameters directly lead to insufficient or excessive heat input. Thus, microcracks and residual stresses are easily formed inside the workpiece, which will have a profound impact on phase transformation and grain refinement of titanium alloy. Therefore, the optimal selection of process parameters is of vital importance.

At present, the main problem of laser-polished Ti6Al4V alloy is the emerging residual stress because of the rapid melting and solidification under the laser irradiation. If the residual stress is too large, it will decrease the fatigue life, which will affect the applications in the aerospace, biomedical, and other fields. In addition to residual stress, how to suppress the phase transformation during the laser polishing of titanium alloy is also a problem that needs to be solved at present. If researchers can solve these problems, it will bring huge opportunities for the industrial application of laser-polished Ti6Al4V alloy.

Currently, there are few articles about laser polishing of Ti6Al4V alloy. In the future, the following aspects can be studied.

(1) It is necessary to thoroughly study the reason for the change of microstructure and mechanical properties of titanium alloy after laser polishing and to accurately control the performance of the workpiece by optimizing the process parameters.

(2) The heat conduction and fluid dynamics in the process of melting and resolidification can be studied by numerical simulation to analyze their influence on the surface morphology.

(3) By selecting the appropriate laser source and establishing a mathematical model, the mechanism of laser polishing can be further analyzed.

\section{Acknowledgments}

This work was supported by the National Natural Science Foundation of China (Grant No. 51675270). The authors declare that they have no known competing financial interests or personal relationships that could have appeared to influence the work reported in this paper. 


\section{References}

1. J. P. Kruth et al., "Consolidation phenomena in laser and powder-bed based layered manufacturing," CIRP Ann.-Manuf. Technol. 56(2), 730-759 (2007).

2. C. Y. Yap et al., "Review of selective laser melting: materials and applications," Appl. Phys. Rev. 2(4), 041101 (2015).

3. Z. F. Chen et al., "Review on residual stress in selective laser melting additive manufacturing of alloy parts," Opt. Laser Technol. 129, 106283 (2020).

4. F. G. Arcella and F. H. Froes, "Producing titanium aerospace components from powder using laser forming," JOM 52(5), 28-30 (2000).

5. S. Tammas-Williams et al., "XCT analysis of the influence of melt strategies on defect population in Ti-6Al-4V components manufactured by selective electron beam melting," Mater. Charact. 102, 47-61 (2015).

6. M. Gharbi et al., "Influence of a pulsed laser regime on surface finish induced by the direct metal deposition process on a Ti64 alloy," J. Mater. Process. Technol. 214(2), 485-495 (2014).

7. S. Pal et al., "As-fabricated surface morphologies of Ti-6Al-4V samples fabricated by different laser processing parameters in selective laser melting," Additive Manuf. 33, 101147 (2020).

8. C. C. Ng et al., "Layer manufacturing of magnesium and its alloy structures for future applications," Virtual Phys. Prototyp. 5(1), 13-19 (2010).

9. E. O. Olakanmi, R. F. Cochrane, and K. W. Dalgarno, "A review on selective laser sintering/ melting (SLS/SLM) of aluminium alloy powders: processing, microstructure, and properties," Prog. Mater. Sci. 74,401-477 (2015).

10. E. O. Olakanmi, "Selective laser sintering/melting (SLS/SLM) of pure $\mathrm{Al}, \mathrm{Al}-\mathrm{Mg}$, and Al-Si powders: effect of processing conditions and powder properties," J. Mater. Process. Technol. 213(8), 1387-1405 (2013).

11. K. C. Wong et al., "One-step reconstruction with a 3D-printed, biomechanically evaluated custom implant after complex pelvic tumor resection," Comput. Aided Surg. 20(1), 14-23 (2015).

12. C. Y. Liang et al., "Laser polishing of Ti6Al4V fabricated by selective laser melting," Metals 10(2), 191-203 (2020).

13. J. Koopmann, J. Voigt, and T. Niendorf, "Additive manufacturing of a steel-ceramic multimaterial by selective laser melting," Metallurg. Mater. Trans. B. 50(2), 1042-1051 (2019).

14. K. D. Leedy and J. F. Stubbins, "Copper alloy-stainless steel bonded laminates for fusion reactor applications: crack growth and fatigue," Mater. Sci. Eng. A. 297, 19-25 (2001).

15. O. Yilmaz and H. Celik, "Electrical and thermal properties of the interface at diffusionbonded and soldered 304 stainless steel and copper bimetal," J. Mater. Process. Technol. 141, 67-76 (2003).

16. S. Mohanty and J. H. Hattel, "Laser additive manufacturing of multimaterial tool inserts: a simulation-based optimization study," Proc. SPIE 10095, 100950G (2017).

17. M. G. Scaramuccia et al., "Development of processing strategies for multigraded selective laser melting of Ti6Al4V and IN718," Powder Technol. 367, 376-389 (2020).

18. D. Fu et al., "Simulation research on the grinding forces and stresses distribution in singlegrain surface grinding of Ti-6Al-4V alloy when considering the actual cutting-depth variation," Int. J. Adv. Manuf. Technol. 91(9-12), 3591-3602 (2017).

19. Q. L. An and J. Q. Dang, "Cooling effects of cold mist jet with transient heat transfer on high-speed cutting of titanium alloy," Int. J. Precis. Eng. Manuf. Green Technol. 7(2), 271-282 (2020).

20. J. W. Wang et al., "Fracture mechanism of polycrystalline cubic boron nitride abrasive grains during single-grain grinding of Ti-6Al-4V titanium alloy," Int. J. Adv. Manuf. Technol. 94(1-4), 281-291 (2018).

21. S. Palanivel et al., "Spatially dependent properties in a laser additive manufactured Ti-6Al-4V component," Mater. Sci. Eng. A 654, 39-52 (2016).

22. S. P. L. Kumar and D. Avinash, "Review on effect of Ti-alloy processing techniques on surface-integrity for biomedical application," Mater. Manuf. Process. 35(8), 869-892 (2020). 
23. S. A. Tsipas, E. Gordo, and A. Jiménez-Morales, "Oxidation and corrosion protection by halide treatment of powder metallurgy Ti and Ti6Al4V alloy," Corros. Sci. 88, 263-274 (2014).

24. M. S. I. Chowdhury et al., "Wear behaviour of coated carbide tools during machining of Ti6Al4V aerospace alloy associated with strong built up edge formation," Surf. Coat. Technol. 313, 319-327 (2017).

25. B. Baufeld, O. V. D. Biest, and R. Gault, "Additive manufacturing of Ti-6Al-4V components by shaped metal deposition: microstructure and mechanical properties," Mater. Design 31, s106-s111 (2010).

26. H. Gong et al., "Analysis of defect generation in Ti-6Al-4V parts made using powder bed fusion additive manufacturing processes," Addit. Manuf. 1-4, 87-98 (2014).

27. K. P. Cooper, "Building components by laser-additive processing," JOM 53(9), 29 (2001).

28. G. Strano et al., "Surface roughness analysis, modelling and prediction in selective laser melting," J. Mater. Process. Technol. 213(4), 589-597 (2013).

29. D. Wang et al., "Theoretical and experimental study on surface roughness of 316L stainless steel metal parts obtained through selective laser melting," Rapid Prototyp. J. 22(4), 706716 (2016).

30. B. B. He et al., "Microstructural characteristic and mechanical property of Ti6Al4V alloy fabricated by selective laser melting," Vacuum 150, 79-83 (2018).

31. S. Cao et al., "Role of martensite decomposition in tensile properties of selective laser melted Ti-6Al-4V," J. Alloys Comp. 744,357-363 (2018).

32. Z. C. Fang et al., "Review on residual stress in selective laser melting additive manufacturing of alloy parts," Opt. Laser Technol. 129,106283 (2020).

33. K. L. Tan and S. H. Yeo, "Surface finishing on IN625 additively manufactured surfaces by combined ultrasonic cavitation and abrasion," Addit. Manuf. 31, 100938 (2020).

34. F. Scherillo, "Chemical surface finishing of AlSi10Mg components made by additive manufacturing," Manuf. Lett. 19, 5-9 (2019).

35. M. Kahlin et al., "Improved fatigue strength of additively manufactured Ti6Al4V by surface post processing," Int. J. Fatigue 134, 105497 (2020).

36. E. Łyczkowska et al., "Chemical polishing of scaffolds made of Ti-6Al-7Nb alloy by additive manufacturing," Arch. Civil Mech. Eng. 14(4), 586-594 (2014).

37. R. Avilés et al., "Influence of laser polishing on the high cycle fatigue strength of medium carbon AISI 1045 steel," Int. J. Fatigue. 33(11), 1477-1489 (2011).

38. C. P. Ma, Y. C. Guan, and W. Zhou, "Laser polishing of additive manufactured Ti alloys," Opt. Lasers Eng. 93, 171-177 (2017).

39. A. Krishnan and F. Fang, "Review on mechanism and process of surface polishing using lasers," Front. Mech. Eng. 14(3), 299-319 (2019).

40. A. Temmler, E. Willenborg, and K. Wissenbach, "Laser polishing. Laser applications in microelectronic and optoelectronic manufacturing (LAMOM)," Proc. SPIE 8243, 8243OW (2012).

41. V. Alfieri et al., "Reduction of surface roughness by means of laser processing over additive manufacturing metal parts," Materials 10(1), 30 (2016).

42. Y. T. Tian et al., "Material interactions in laser polishing powder bed additive manufactured Ti6Al4V components," Addit. Manuf. 20, 11-22 (2018).

43. J. A. Ramos-Grez and D. L. Bourell, "Reducing surface roughness of metallic freeformfabricated parts using non-tactile finishing methods," Int. J. Mater. Prod. Technol. 21(4), 297-316 (2004).

44. L. Zhao et al., "Laser polishing for topography management of accelerator cavity surfaces," Mater. Werkstofftech. 46(7), 675-685 (2015).

45. J. A. Ramos, D. L. Bourell, and J. J. Beaman, "Surface over-melt during laser polishing of indirect-SLS metal parts," MRS Proc. 758, 19 (2002).

46. S. M. Basha et al., "Laser polishing of 3D printed metallic components: a review on surface integrity," Mater. Today: Proc. 26, 2047-2054 (2020).

47. K. C. Yung et al., "Laser polishing of additive manufactured tool steel components using pulsed or continuous-wave lasers," Int. J. Adv. Manuf. Technol. 105, 425-440 (2019). 
48. J. Zhou et al., "Surface and property characterization of laser polished Ti6Al4V," Surf. Coat. Technol. 380, 125016 (2019).

49. P. Jaritngam et al., "Surface and subsurface characteristics of laser polished Ti6Al4V titanium alloy," Opt. Laser Technol. 126, 106102 (2020).

50. D. Q. Zhang et al., "Investigation of laser polishing of four selective laser melting alloy samples," Appl. Sci. 10(3), 760 (2020).

51. S. Marimuthu et al., "Laser polishing of selective laser melted components," Int. J. Mach. Tools Manuf. 95, 97-104 (2015).

52. Y. H. Li et al., "Material characterization, thermal analysis, and mechanical performance of a laser-polished Ti alloy prepared by selective laser melting," Metals 9(2), 112 (2019).

53. F. E. Pfefferkorn et al., "Improving surface finish in pulsed laser micro polishing using thermocapillary flow," CIRP Ann. - Manuf. Technol. 62, 203-206 (2013).

54. J. Vaithilingam et al., "The effect of laser remelting on the surface chemistry of Ti6al4V components fabricated by selective laser melting," J. Mater. Process. Technol. 232, 1-8 (2016).

55. S. Leuders et al., "On the mechanical behaviour of titanium alloy TiAl6V4 manufactured by selective laser melting: fatigue resistance and crack growth performance," Int. J. Fatigue 48, 300-307 (2013).

56. A. R. Nassar et al., "Intra-layer closed-loop control of build plan during directed energy additive manufacturing of Ti-6Al-4V," Addit. Manuf. 6, 39-52 (2015).

57. Y. C. Zhong, I. H. Ahn, and S. K. Moon, "Process monitoring and inspection systems in metal additive manufacturing: status and applications," Int. J. Precis. Eng. Manuf.-Green Technol. 4(2), 235-245 (2017).

58. C. Ma et al., "Melt pool flow and surface evolution during pulsed laser micro polishing of Ti6Al4V," in Proc. ASME 2013 Int. Manuf. Sci. and Eng. Conf., Madison, Wisconsin (2013).

59. A. Raghavan et al., "Heat transfer and fluid flow in additive manufacturing," J. Laser Appl. 25(5), 052006 (2013).

60. L. Parry, I. A. Ashcroft, and R. D. Wildman, "Understanding the effect of laser scan strategy on residual stress in selective laser melting through thermo-mechanical simulation," Addit. Manuf. 12, 1-15 (2016).

61. I. Yadroitsev and I. Yadroitsava, "Evaluation of residual stress in stainless steel 316L and Ti6Al4V samples produced by selective laser melting," Virtual Phys. Prototyp. 10(2), 67-76 (2015).

Jiejing Li is a PhD candidate in the College of Mechanical and Electrical Engineering, Nanjing University of Aeronautics and Astronautics. She received her master's degree in mechanical engineering in June 2019. Her research areas include laser polishing and ultraprecision machining, and she has contributed to some scientific journals.

Dunwen Zuo is a professor and $\mathrm{PhD}$ supervisor in the College of Mechanical and Electrical Engineering, Nanjing University of Aeronautics and Astronautics. He is mainly engaged in precision machining technology, micro nano machining technology research, etc. He has published more than 300 papers in important journals and academic conferences at home and abroad. 